\title{
AUSTERIDADE, EMPREGO E REGIME DE BEM-ESTAR SOCIAL EM PORTUGAL: EM PROCESSO DE REFAMILIZAÇÃO?
}

\author{
Virginia Ferreira e Rosa Monteiro
}

Faculdade de Economia da Universidade de Coimbra/ Centro de Estudos Sociais, Portugal Instituto Superior Miguel Torga/Centro de Estudos Sociais, Portugal

\section{Resumo}

Este trabalho parte do pressuposto de que a crise não é neutra, antes tendo impactos diferenciados nas condições de vida de mulheres e de homens. Analisamos os impactos da crise e das medidas tomadas em nome do seu combate pelos XVIII e XIX Governos Constitucionais, desde 2009, bem como os respetivos efeitos complexos e diferenciados sobre a situação individual, social e económica de mulheres e homens, em Portugal. Exploramos a forma como as transformações ocorridas no emprego, e nas condições de proteção social associadas determinam uma generalização da precariedade a ambos os sexos, e perdas significativas de autonomia para as mulheres, refamilização dos cuidados e um risco de retorno a um passado desigualitário e assimétrico.

Palavras-chave: austeridade, emprego, refamilização, regime de bem-estar social, Portugal.

\section{Abstract}

Austerity, employment and welfare regime in Portugal: in a process of refamilisation?

This paper assumes that the crisis is not neutral, having different impacts on the living conditions of women and men. We analyse the impacts of the crisis and of the measures taken to tackle it by the 18th and 19th Constitutional Governments since 2009. We analyse as well its complex and differentiated effects on individual, social and economic situation of women and men in Portugal. The paper explores how the changes occurred in employment and associated social protection conditions determine a generalization of job precariousness to both sexes, and significant losses of autonomy for women, refamilisation of care and a significant risk of return to an unequal and unbalanced past.

Keywords: austerity, employment, refamilisation, welfare regime, Portugal.

\section{Resumen}

Austeridad, empleo e regimen de bienestar social en Portugal: en processo de refamilización?

En este trabajo se asume que la crisis no es neutral, pero que tienen diferentes impactos en las condiciones de vida de mujeres y hombres. Hemos analizado los impactos de la crisis y de las medidas adoptadas para combatirla por los XVIII y XIX gobiernos constitucionales, desde el año 2009. Analizamos también los respectivos efectos complejos y diferenciados sobre la situación individual, social y económica de las mujeres y de los hombres en Portugal. El artículo explora cómo los cambios en el empleo y en las condiciones de protección social asociadas están determinando una generalización de la precariedad laboral a ambos sexos, y la pérdida significativa de la autonomía de las mujeres, refamilización de los cuidados y el riesgo de regreso a un pasado desigual y desequilibrado.

Palabras-clave: austeridad, empleo, refamilización, régimen de bienestar, Portugal. 


\section{Introdução}

A crise financeira que despontou na Europa em 2008 teve impactos particularmente dramáticos em países com grandes dívidas soberanas como é o caso de Portugal. Já antes da crise económico-financeira internacional, Portugal era um país endividado devido a décadas de reduzido crescimento económico. A dívida expôs o país a vulnerabilidades económicas acrescidas, que o impediram de se financiar nos mercados e levaram à intervenção externa através de um Programa de assistência. Com efeito, a dívida pública cresceu de $60 \%$ do PIB, em meados da década de 2000, para os $90 \%$ em 2010, o que pressionou o governo português a sucumbir aos mercados financeiros e especulativos e a pedir um empréstimo às instituições europeias. O empréstimo, de 75 biliões de euros, foi aprovado em maio de 2011, pelas instituições internacionais receosas de uma bancarrota na zona euro.

Desde então Portugal vive numa situação declarada de crise, que suscitou a intervenção de uma troica de instituições internacionais (Comissão Europeia, Banco Central Europeu e Fundo Monetário Internacional) e a imposição de um conjunto de severas medidas austeritárias. Como Santos (2011) a qualifica, a crise é de natureza financeira (de financiamento do Estado), económica (de competitividade) e cultural e política (de omissão e de falta de acerto das soluções apresentadas).

Os sinais mais dramáticos da crise têm-se traduzido nos cortes dos salários e pensões, no aumento do desemprego e da carga fiscal, no aumento dos preços dos bens e do crédito a particulares ou empresas, no aumento do endividamento e diminuição do rendimento disponível das famílias, na emigração, e na redução drástica da proteção social e de apoio na saúde, numa severa retração do estado-providência (Ferreira, 2014; González e Figueiredo, 2014; Zartaloudis, 2014). Face a estas políticas, a resposta das famílias foi a de cortarem no consumo, reconfigurando gastos habituais e supérfluos; quase 500 mil pessoas emigraram, desde 2011 ${ }^{1}$; outras procuraram um segundo trabalho (muitas vezes informal). Mais do que a mobilização institucional, estas formas de automobilização e a procura de solidariedade intergeracional intrafamiliar permitiram ajustamentos orçamentais e financeiros nas famílias, responsáveis pela manutenção da estabilidade social e destacaram-se como estratégias privilegiadas de reação aos impactos da crise (Frade e Coelho, 2015).

A nível macroeconómico o regime de austeridade acrescentou estagnação económica, quebra no investimento privado e público, paralisação do crescimento da economia, redução do Produto Interno Bruto, aprofundando as desigualdades socais e o empobrecimento.

Tal como qualquer outro fenómeno, a crise não é neutra, antes tem impactos diferenciados nas mulheres e nos homens. O que nos propomos fazer é proceder a uma análise desses impactos, da crise e das medidas tomadas em nome do seu combate pelos XVIII e XIX Governos Constitucionais, desde 2009, sobre a situação individual, social e económica de mulheres e homens. Prosseguindo este objetivo,

\footnotetext{
485.128 pessoas no conjunto dos quatro anos; 134.624 só em 2014, segundo o INE (2015b).
} 
procede-se neste trabalho a uma análise sobre a evolução interrelacionada ao longo da crise das relações e mercado laborais e do Estado de bem-estar, tendo em conta as diferentes situações e condições de vida de mulheres e homens.

Os impactos da crise e da austeridade no regime de bem-estar social refletir-se-ão necessariamente nas alterações aos padrões de comparticipação para o bem-estar social do Estado, do mercado e da família e aos padrões de divisão sexual do trabalho pago e não pago. Procuraremos respostas, ainda que parciais, a algumas questões emergentes: - Menos desigualdade entre mulheres e homens ou o seu inverso? Regresso ao modelo fordista do homem provedor da família ou persistência das famílias de dupla carreira? Externalização do trabalho doméstico e da prestação de cuidados ou (re)familização? Queremos conhecer a forma como a crise e as políticas destinadas ao seu combate têm produzido alterações no mercado de trabalho e têm contribuído para uma reversão nos processos de construção dos regimes de bem-estar e de sexo/género encetados nas últimas décadas.

\section{Efeitos da crise sobre o mercado de trabalho}

A estrutura de emprego em Portugal é altamente feminizada, mas também altamente segregada segundo o sexo, o que determina que os efeitos da crise, especialmente na sua fase inicial mais sectorial, incidam de modo diferente em mulheres e homens.

Portugal começou a perder emprego no início de 2009. Desde então até dezembro de 2014, os homens perderam 464,9 mil postos de trabalho e as mulheres 211,9 mil, números que correspondem a cerca de $-17 \%$ e -9\%, do respetivo volume de emprego (tabela 1). Para além da elevada participação feminina no mercado de trabalho, em Portugal, tem-se registado uma tendência para a redução do diferencial de emprego dos homens e das mulheres. O grupo entre os 15 e os 24 anos é um dos mais afetados pela crise, com um aumento extraordinário do desemprego (mais de 35\%, para ambos os sexos, a partir de meados de 2012) (INE, 2015a).

O emprego masculino foi o primeiro a ser afetado pela crise, sendo que logo desde janeiro de 2009, a redução de empregos foi acentuada especialmente no setor industrial do ramo automóvel e no da construção. Esta variação levou a que se pensasse que a recessão observada afetasse mais os homens do que as mulheres, cunhada esta ideia na noção de «mancession» (McKay et al., 2013: 112) ou de «he-cession» (Rubery, 2013). Só um ano mais tarde o emprego feminino viria a ser afetado. Entre 2008 e 2011, dois em cada três empregos perdidos eram ocupados por homens (Ferreira, 2014: 213). Em termos absolutos, os homens perderam emprego essencialmente como assalariados e as mulheres como trabalhadoras independentes isoladas (duas vezes mais do que os homens). Em termos relativos, as situações no emprego mais afetadas foram as do trabalho familiar não remunerado, que viu os seus efetivos reduzirem-se praticamente a metade, tanto nos homens como nas mulheres. A hipótese que colocamos é a de que muitas 
destas pessoas deixaram de poder trabalhar na atividade independente que algum familiar possuía e encerrou. Por seu turno, as mulheres trabalhadoras independentes registaram uma taxa de variação igualmente extraordinária, em resultado da eliminação de quase metade dos efetivos nesta categoria $(-48,5 \%)$.

$\mathrm{O}$ aumento significativo dos homens e das mulheres com 15 anos ou mais em inatividade revela que parte significativa desistiu de procurar emprego. Mais uma vez a taxa de variação, neste caso positiva, da população masculina é o dobro da feminina.

Tabela 1

Perdas e ganhos líquidos de empregos por estatuto de emprego e sexo (2008/2014)

\begin{tabular}{|c|c|c|c|c|c|c|c|}
\hline \multirow{2}{*}{$\begin{array}{c}\text { Situação } \\
\text { no Emprego }\end{array}$} & \multirow[b]{2}{*}{ Sexo } & \multicolumn{2}{|c|}{2008} & \multicolumn{2}{|c|}{2014} & \multicolumn{2}{|c|}{ Variação 2008-2014 $(\Delta)^{*}$} \\
\hline & & $\mathrm{Em}, 000$ & Peso em \% & $\mathrm{Em}, 000$ & Peso em \% & Em, 000 & $\begin{array}{c}\text { Variação } \\
\text { 2008-2014 (\%) }\end{array}$ \\
\hline \multirow{2}{*}{ Total do Emprego } & M & 2797,1 & 100,0 & 2319,5 & 100 & $-477,6$ & $-17,1$ \\
\hline & $\mathrm{F}$ & 2400,7 & 100,0 & 2180,0 & 100 & $-220,7$ & $-9,2$ \\
\hline \multirow{2}{*}{$\begin{array}{l}\text { Trab. Por Conta } \\
\text { de Outrem (TPCO) }\end{array}$} & M & 2086,9 & 74,6 & 1754,9 & 75,7 & $-332,0$ & $-15,9$ \\
\hline & $\mathrm{F}$ & 1862,8 & 77,6 & 1856,1 & 85,1 & $-6,7$ & $-0,4$ \\
\hline \multirow{2}{*}{ Trabalhad. Independentes } & M & 481,5 & 17,2 & 387,4 & 16,7 & $-94,1$ & $-19,5$ \\
\hline & $\mathrm{F}$ & 428,9 & 17,9 & 243,1 & 11,2 & $-185,8$ & $-43,3$ \\
\hline Trab. Independentes & M & 207,6 & 7,4 & 166,4 & 7,2 & $-41,2$ & $-19,8$ \\
\hline Empregadores/as & $\mathrm{F}$ & 79,6 & 3,3 & 67,6 & 3,1 & $-12,0$ & $-15,1$ \\
\hline \multirow{2}{*}{$\begin{array}{l}\text { Trabalhad. Familiares } \\
\text { não Remunerados/as }\end{array}$} & M & 21,1 & 0,8 & 10,8 & 0,5 & $-10,3$ & $-48,8$ \\
\hline & $\mathrm{F}$ & 29,4 & 1,2 & 13,2 & 0,6 & $-16,2$ & $-55,1$ \\
\hline \multirow{2}{*}{ Inativos $(15 \mathrm{e}+$ anos $)$} & M & 1316,9 & & 1474,5 & & 157,6 & 12,0 \\
\hline & $\mathrm{F}$ & 2056,3 & & 2183,3 & & 127,0 & 6,2 \\
\hline
\end{tabular}

Fonte: Cálculos próprios. Com base nas Estatísticas do Emprego - 4..$^{\circ}$ Trimestre (INE 2009; 2012; 2015a).

* O símbolo $\Delta$ indica que foi calculada a variação em percentagem entre um valor ou quantidade anterior e um valor ou quantidade posterior traduzida na fórmula $(\mathrm{V} 2-\mathrm{V} 1) / \mathrm{V} 1 \times 100$.

Entre 2008 e 2014, como vimos, a taxa de variação do emprego masculino atingiu quase o dobro da do feminino (-17,1\% vs. $-9,2 \%)$. A situação que mais pesa nesta diferença é a taxa de variação quase nula $(-0,4 \%)$ do emprego feminino por conta de outrem (TPCO), em grande contraste com a do emprego masculino na mesma situação, que atingiu quase os $-16 \%$ negativos. Uma vez que três pessoas em cada quatro que têm um emprego fazem-no por conta de outrem, o que acontece nesta categoria acaba por determinar a tendência a nível agregado. Nas outras situações de emprego (principalmente no trabalho independente, mas também no trabalho não remunerado no seio da família), foi o emprego feminino que registou uma quebra que atingiu quase o dobro da do masculino $(-39,8 \%$ vs $-20,5 \%)$. Em suma, os trabalhadores por conta de outrem e as trabalhadoras por conta 
própria foram, com efeito, os segmentos da oferta de trabalho mais afetados pela destruição de postos de trabalho durante os seis anos de crise em análise.

Estes dados contrariam a noção comum de que as pessoas uma vez desempregadas se lançarão a criar o próprio emprego, trabalhando por conta própria. Tem havido, de facto, um enorme investimento discursivo (e, em certos casos, financeiro) na promoção do empreendedorismo, nomeadamente das mulheres. Ao contrário, estes dados demonstram bem a maior vulnerabilidade do trabalho por conta própria, que mais rapidamente se ajusta a quebras na procura. É importante não ignorar que na categoria de trabalho independente se encontram muitas situações de falso trabalho independente ou de «falsos recibos verdes». As pessoas nesta situação vivenciam condições laborais bastante precárias nas quais lhes são suprimidos muitos direitos e benefícios: as entidades empregadoras não pagam a taxa de $23,7 \%$ da contribuição e podem «dispensar» os/as trabalhadores/as «independentes» quando querem. Estes/as trabalhadores/as, por seu turno, têm de pagar as contribuições que são mais elevadas do que aquelas a que está obrigado quem trabalha por conta de outrem, e são objeto de menor proteção pela segurança social. Desde 2013, porém, que as pessoas nesta situação passaram a ter direito a proteção na doença, desemprego, parentalidade, doenças profissionais, invalidez, velhice e morte, muito embora com respostas mínimas que ficam aquém das que obtém quem trabalha por conta de outrem².

As mudanças fiscais introduzidas em janeiro de 2011 explicam parte da redução das taxas de emprego por conta própria, uma vez que as entidades empregadoras passaram a pagar 5\% por cada «trabalhador/a independente» e estes/as viram as suas contribuições aumentar para $29,6 \%{ }^{3}$. A introdução desta contribuição de $5 \%$ pode ter tido como efeito que algumas pessoas a trabalhar a recibos verdes passaram a ter um contrato de trabalho ${ }^{4}$.

O Decreto-Lei no 65/2012, 15 de março, procurou alargar a proteção dos chamados «falsos recibos verdes» abrangendo «os trabalhadores independentes que, no mesmo ano civil, obtenham da mesma empresa, seja ela uma pessoa coletiva ou uma pessoa singular com atividade empresarial, independentemente da sua natureza e das finalidades que prossigam, $80 \%$ ou mais do valor total anual dos rendimentos obtidos na atividade independente. Por seu turno, o DecretoLei $n^{\circ}$ 12/2013, de 25 de janeiro, estabelece o regime jurídico de proteção social na eventualidade de desemprego de trabalhadores/as independentes com atividade empresarial e dos membros dos órgãos estatutários das pessoas coletivas. A informação completa sobre estatuto de trabalho independente, contribuições e direitos pode ser consultada em: http://www4.segsocial.pt/documents/10152/14965/inscricao admissao cessacao actividade ti; http://www4. seg-social.pt/documents/10152/13198/trabalhadores_independentes.

3 Conforme estabelecido pela Lei no 110/2009, de 16 de setembro.

4 É essa a penalização que a Autoridade para as Condições de Trabalho (ACT) impõe às empresas denunciadas pela Segurança Social. Através da análise dos descontos dos/as trabalhadores/as para a Segurança Social é possível perceber se $80 \%$ ou mais dos rendimentos provêm de uma única entidade. Em 2014, foram detetadas 1510 situações de «falsos recibos verdes», tendo $34 \%$ visto a sua situação regularizada através da celebração de contrato de trabalho (ACT, 2015). 
Para um melhor entendimento de qual tem sido a variação líquida do emprego e quem tem sido mais afetado pela sua redução ou aumento, analisámos a variação do emprego por sexo, por setor de atividade e por situação na profissão ${ }^{5}$. Na análise das variações do emprego por situação na profissão, distinguimos apenas entre o trabalho por conta de outrem (TPCO) (três quartos das pessoas empregadas) e as Outras Situações, nas quais incluímos o trabalho independente e o trabalho não remunerado no seio da família (este com expressão residual). Na primeira tabela apresentamos a variação do emprego e na segunda quantificamos o impacto que essa variação teve na taxa de feminização de cada um dos tipos de emprego.

Tabela 2

Mudanças no emprego por setor, situação na profissão e sexo (2008-2014)

\begin{tabular}{|c|c|c|c|c|c|c|c|}
\hline \multirow[b]{2}{*}{ Atividade principal } & \multirow[b]{2}{*}{ Sexo } & \multicolumn{3}{|c|}{$\begin{array}{c}\text { Variação do emprego } \\
\text { (milhares de indivíduos) }\end{array}$} & \multicolumn{3}{|c|}{$\begin{array}{c}\text { Variação do emprego }(\Delta)^{*} \\
(\mathrm{em} \%)\end{array}$} \\
\hline & & $\begin{array}{c}\text { Emprego } \\
\text { Total } \\
2008-2014\end{array}$ & $\begin{array}{c}\text { TPCO } \\
\text { 2008-2014 }\end{array}$ & $\begin{array}{c}\text { Outras } \\
\text { Situações } \\
\text { 2008-2014 }\end{array}$ & \begin{tabular}{|c|} 
Emprego \\
Total \\
2008-2014
\end{tabular} & $\begin{array}{c}\text { TPCO } \\
\text { 2008-2014 }\end{array}$ & $\begin{array}{c}\text { Outras } \\
\text { Situações } \\
\text { 2008-2014 }\end{array}$ \\
\hline \multirow[t]{2}{*}{ Todos os setores } & M & $-477,6$ & $-332,0$ & $-145,6$ & $-17,1$ & $-15,9$ & $-20,5$ \\
\hline & F & $-220,7$ & $-6,7$ & $-214,0$ & $-9,2$ & $-0,4$ & $-39,8$ \\
\hline \multirow[t]{2}{*}{ Agric., caça e floresta } & M & $-38,4$ & $-1,3$ & $-37,1$ & $-13,7$ & $-2,5$ & $-16,2$ \\
\hline & $\mathrm{F}$ & $-147,4$ & $-0,7$ & $-146,7$ & $-52,0$ & $-2,6$ & $-57,2$ \\
\hline \multirow[t]{2}{*}{ Pesca e aquacultura } & $\mathrm{M}$ & $-6,4$ & $-2,7$ & $-3,7$ & $-37,6$ & $-26,2$ & $-55,2$ \\
\hline & $\mathrm{F}$ & 0,1 & 0,4 & $-0,3$ & 11,1 & 133,3 & $-50,0$ \\
\hline \multirow[t]{2}{*}{ Ind. extractivas } & $\mathrm{M}$ & $-5,1$ & $-5,0$ & $-0,1$ & $-30,9$ & $-31,8$ & $-12,5$ \\
\hline & $\mathrm{F}$ & $-0,6$ & $-0,4$ & $-0,2$ & $-40,0$ & $-30,8$ & $-100,0$ \\
\hline \multirow[t]{2}{*}{ Indústrias transformadoras } & $\mathrm{M}$ & $-85,6$ & $-76,1$ & $-9,5$ & $-16,3$ & $-16,4$ & $-15,3$ \\
\hline & $\mathrm{F}$ & $-69,4$ & $-62,8$ & $-6,6$ & $-18,8$ & $-18,4$ & $-25,2$ \\
\hline \multirow{2}{*}{$\begin{array}{l}\text { Eletricidade, gás, vapor, água } \\
\text { e ar frio }\end{array}$} & $\mathrm{M}$ & $-6,6$ & $-6,4$ & $-0,2$ & $-35,3$ & $-35,4$ & $-33,3$ \\
\hline & F & $-1,5$ & $-1,6$ & 0,1 & $-33,3$ & $-35,6$ & n.d. \\
\hline \multirow{2}{*}{$\begin{array}{l}\text { Captação, tratamento e } \\
\text { distribuição de água, resíduos }\end{array}$} & $\mathrm{M}$ & $-3,9$ & $-4,5$ & 0,6 & $-13,9$ & $-16,5$ & 66,7 \\
\hline & $\mathrm{F}$ & 0,4 & 0,5 & $-0,1$ & 6,0 & 7,8 & $-33,3$ \\
\hline \multirow{2}{*}{ Construção } & $\mathrm{M}$ & $-272,2$ & $-208,0$ & $-64,2$ & $-51,3$ & $-51,1$ & $-51,8$ \\
\hline & F & $-7,1$ & $-3,3$ & $-3,8$ & $-29,5$ & $-18,9$ & $-57,6$ \\
\hline \multirow{2}{*}{$\begin{array}{l}\text { Comércio grosso, retalho, } \\
\text { Repar. veiculos motores }\end{array}$} & $\mathrm{M}$ & $-77,9$ & $-55,4$ & $-22,5$ & $-18,3$ & $-18,6$ & $-17,6$ \\
\hline & F & $-18,5$ & 2,1 & $-20,6$ & $-5,4$ & 0,8 & $-25,1$ \\
\hline
\end{tabular}

5 No $1^{\circ}$ trimestre de 2011 a definição de categorias e a metodologia mudou no Inquérito ao Emprego, tornando a quebra de série inviáveis comparações diretas, nomeadamente, nos dados do desemprego, donde termos optado por incidir a análise nas variações do volume de emprego nas várias situações, pois, embora também neste indicador tenham existido alterações nos métodos de cálculo, consideramos que o seu impacto é hipoteticamente menor do que no caso do desemprego. 
Tabela 2 (continuação)

Mudanças no emprego por setor, situação na profissão e sexo (2008-2014)

\begin{tabular}{|c|c|c|c|c|c|c|c|}
\hline \multirow[b]{2}{*}{ Atividade principal } & \multirow[b]{2}{*}{ Sexo } & \multicolumn{3}{|c|}{$\begin{array}{c}\text { Variação do emprego } \\
\text { (milhares de indivíduos) }\end{array}$} & \multicolumn{3}{|c|}{$\begin{array}{c}\text { Variação do emprego }(\Delta)^{*} \\
(\text { em \%) }\end{array}$} \\
\hline & & $\begin{array}{c}\text { Emprego } \\
\text { Total } \\
2008-2014\end{array}$ & $\begin{array}{c}\text { TPCO } \\
2008-2014\end{array}$ & $\begin{array}{c}\text { Outras } \\
\text { Situações } \\
2008-2014\end{array}$ & $\begin{array}{c}\text { Emprego } \\
\text { Total } \\
2008-2014\end{array}$ & $\begin{array}{c}\text { TPCO } \\
2008-2014\end{array}$ & $\begin{array}{c}\text { Outras } \\
\text { Situações } \\
2008-2014\end{array}$ \\
\hline \multirow{2}{*}{ Transporte, armazenagem } & M & $-3,9$ & 4,9 & $-8,8$ & $-2,6$ & 4,0 & $-37,3$ \\
\hline & $\mathrm{F}$ & 1,7 & 1,2 & 0,5 & 5,6 & 4,3 & 25,0 \\
\hline \multirow{2}{*}{$\begin{array}{l}\text { Alojamento, restauração, } \\
\text { similares }\end{array}$} & M & $-10,4$ & $-0,4$ & $-10,0$ & $-8,1$ & $-0,5$ & $-20,1$ \\
\hline & $\mathrm{F}$ & $-32,6$ & $-17,6$ & $-15,0$ & $-17,0$ & $-12,1$ & $-32,5$ \\
\hline \multirow{2}{*}{$\begin{array}{l}\text { Atividades de Informação } \\
\text { e de comunicação }\end{array}$} & M & 15,7 & 13,9 & 1,8 & 26,9 & 27,8 & 21,7 \\
\hline & $\mathrm{F}$ & $-2,7$ & $-3,8$ & 1,1 & $-7,7$ & $-11,6$ & 52,4 \\
\hline \multirow{2}{*}{ At. financeiras e seguros } & M & 1,9 & $-0,3$ & 2,2 & 3,6 & $-0,6$ & 55,0 \\
\hline & $\mathrm{F}$ & 1,9 & 1,6 & 0,3 & 4,3 & 3,9 & 13,6 \\
\hline \multirow{2}{*}{ Atividades mobiliárias } & M & $-0,3$ & $-0,3$ & 0,0 & $-2,0$ & $-3,6$ & 0,0 \\
\hline & $\mathrm{F}$ & 2,9 & 2,4 & 0,5 & 23,2 & 23,3 & 22,7 \\
\hline \multirow{2}{*}{$\begin{array}{l}\text { Atividades consultoria, } \\
\text { científ., técn. e similares }\end{array}$} & M & 6,6 & 7,1 & $-0,5$ & 8,1 & 15,2 & $-1,4$ \\
\hline & $\mathrm{F}$ & $-0,5$ & $-2,7$ & 2,2 & $-0,5$ & $-3,7$ & 10,4 \\
\hline \multirow{2}{*}{$\begin{array}{l}\text { Atividades administrativas } \\
\text { e serviços de apoio }\end{array}$} & $\mathrm{M}$ & 17,5 & 17,3 & 0,2 & 27,2 & 30,8 & 2,5 \\
\hline & $\mathrm{F}$ & 8,8 & 9,3 & $-0,5$ & 12,5 & 14,2 & $-10,0$ \\
\hline \multirow{2}{*}{$\begin{array}{l}\text { Administração pública, defesa, } \\
\text { segurança. social }\end{array}$} & M & $-34,8$ & $-34,6$ & $-0,2$ & $-15,8$ & $-15,7$ & $-25,0$ \\
\hline & F & 9,1 & 9,4 & $-0,3$ & 7,5 & 7,8 & $-30,0$ \\
\hline \multirow{2}{*}{ Educação } & M & $-2,0$ & $-2,0$ & 0,0 & $-2,5$ & $-2,6$ & 0,0 \\
\hline & $\mathrm{F}$ & 14,8 & 12,7 & 2,1 & 5,6 & 4,9 & 53,8 \\
\hline \multirow{2}{*}{ Saúde humana e apoio social } & M & 17,8 & 13,4 & 4,4 & 35,3 & 29,1 & 102,3 \\
\hline & $\mathrm{F}$ & 59,7 & 59,2 & 0,5 & 23,6 & 24,6 & 4,1 \\
\hline \multirow{2}{*}{$\begin{array}{l}\text { Atividades artísticas, de espetá- } \\
\text { culos, desportivas e recreativas }\end{array}$} & M & 5,7 & 5,0 & 0,7 & 21,0 & 23,9 & 11,1 \\
\hline & S F & 5,6 & 6,0 & $-0,4$ & 29,8 & 37,7 & $-13,8$ \\
\hline \multirow{2}{*}{ Outros serviços } & M & 4,2 & 3,1 & 1,1 & 16,7 & 19,1 & 12,4 \\
\hline & $\mathrm{F}$ & 13,5 & 4,6 & 8,9 & 21,0 & 11,9 & 34,6 \\
\hline \multirow{2}{*}{ Agregados domésticos } & M & 0,5 & 0,2 & 0,3 & 25,0 & 10,5 & 300,0 \\
\hline & $\mathrm{F}$ & $-59,0$ & $-23,3$ & $-35,7$ & $-34,0$ & $-17,3$ & $-91,5$ \\
\hline
\end{tabular}

* O símbolo $\Delta$ indica que foi calculada a variação em percentagem entre um valor ou quantidade anterior e um valor ou quantidade posterior traduzida na fórmula (V2-V1)/V1 x 100.

O setor da construção sobressai por empregar, no final de 2014, praticamente metade dos homens que empregava no final de 2008 (-51,3\%). O setor das indústrias transformadoras também merece destaque, pelo peso específico que ainda tem no mercado de trabalho nacional, e pelo facto de apresentar uma elevada taxa de perda de emprego para ambos os sexos (homens $-16,3 \%$; mulheres $-18,8 \%)$.

No sector da administração pública, defesa e segurança social e no da educação, o emprego feminino aumentou e o masculino diminuiu, sendo que no primeiro a taxa de variação do emprego masculino é negativa e praticamente o dobro da do feminino. 
As atividades que criaram emprego para ambos os sexos situam-se todas nos serviços - trata-se das atividades financeiras e de seguros, as administrativas e de apoio, as artísticas, de espetáculos, desportivas e recreativas, as da saúde humana e apoio social e ainda os «outros serviços». Dentre estas, sobressai o setor da saúde que cresceu a uma taxa de $23 \%$, no caso do emprego feminino, e a $35,3 \%$, no do masculino. Dois dos setores incluídos neste grupo, as atividades administrativas e serviços de apoio e os outros serviços, que empregavam em 2014 um pouco mais de 100.000 homens e de 150.000 mulheres, em conjunto, estão entre os que praticam os salários mais baixos, recebendo respetivamente, $17,3 \%$ e 21,9\%, das pessoas que neles trabalham o salário mínimo (GEE, 2015) ${ }^{6}$.

Tabela 3

Mudanças nas taxas de feminização por setor e situação na profissão (2008-2014)

\begin{tabular}{|c|c|c|c|c|c|c|c|c|c|}
\hline \multirow{2}{*}{ Atividade principal } & \multicolumn{3}{|c|}{$\begin{array}{l}\text { Taxa de feminização - } \\
\text { Emprego Total }\end{array}$} & \multicolumn{3}{|c|}{$\begin{array}{c}\text { Taxa de feminização - } \\
\text { TPCO }\end{array}$} & \multicolumn{3}{|c|}{$\begin{array}{c}\text { Taxa de feminização - } \\
\text { Outras Situações }\end{array}$} \\
\hline & $\begin{array}{c}2008 \\
(\%)\end{array}$ & $\begin{array}{c}2014 \\
(\%)\end{array}$ & $\begin{array}{l}\text { Diferencial } \\
\text { (em p.p.) }\end{array}$ & $\begin{array}{c}2008 \\
(\%)\end{array}$ & $\begin{array}{c}2014 \\
(\%)\end{array}$ & $\begin{array}{l}\text { Diferencial } \\
\text { (em p.p.) }\end{array}$ & $\begin{array}{c}2008 \\
(\%)\end{array}$ & $\begin{array}{c}2014 \\
(\%)\end{array}$ & $\begin{array}{l}\text { Diferencial } \\
\text { (em p.p.) }\end{array}$ \\
\hline Todos os setores & 46,2 & 48,4 & 2,3 & 47,2 & 51,4 & 4,2 & 43,1 & 36,5 & $-6,6$ \\
\hline Agricultura, caça e floresta & 50,3 & 36,1 & $-14,3$ & 34,9 & 34,9 & 0,0 & 52,8 & 36,4 & $-16,5$ \\
\hline Pesca e aquacultura & 5,0 & 8,6 & 3,6 & 2,8 & 8,4 & 5,6 & 8,2 & 9,1 & 0,9 \\
\hline Indústrias extractivas & 8,3 & 7,3 & $-1,0$ & 7,6 & 7,8 & 0,1 & 20,0 & 0,0 & $-20,0$ \\
\hline Indúst. transformadoras & 41,2 & 40,4 & $-0,8$ & 42,5 & 41,9 & $-0,6$ & 29,6 & 27,1 & $-2,5$ \\
\hline $\begin{array}{l}\text { Eletricidade, gás, vapor, } \\
\text { ág., ar frio }\end{array}$ & 19,4 & 19,9 & 0,5 & 19,9 & 19,9 & 0,0 & 0,0 & 20,0 & 20,0 \\
\hline $\begin{array}{l}\text { Captação, tratam. e dist. } \\
\text { de água e res. }\end{array}$ & 19,3 & 22,7 & 3,4 & 19,0 & 23,3 & 4,3 & 25,0 & 11,8 & $-13,2$ \\
\hline Construção & 4,3 & 6,2 & 1,8 & 4,1 & 6,7 & 2,5 & 5,1 & 4,5 & $-0,6$ \\
\hline $\begin{array}{l}\text { Com. grosso, retalho, repar. } \\
\text { veicul. motor. }\end{array}$ & 44,4 & 48,0 & 3,6 & 46,3 & 51,7 & 5,3 & 39,2 & 36,9 & $-2,2$ \\
\hline Transporte, armazenagem & 16,9 & 18,1 & 1,2 & 18,5 & 18,5 & 0,0 & 7,8 & 14,5 & 6,6 \\
\hline Alojamento, rest. e símil. & 59,9 & 57,5 & $-2,5$ & 65,0 & 62,1 & $-2,9$ & 48,1 & 43,9 & $-4,2$ \\
\hline At. informação e comunic. & 37,4 & 30,3 & $-7,1$ & 39,6 & 31,2 & $-8,4$ & 20,2 & 24,1 & 3,9 \\
\hline At. financeiras e seguros & 45,4 & 45,6 & 0,2 & 46,1 & 47,2 & 1,1 & 35,5 & 28,7 & $-6,7$ \\
\hline Atividades mobiliárias & 46,0 & 51,7 & 5,7 & 55,1 & 61,1 & 6,0 & 25,9 & 30,0 & 4,1 \\
\hline $\begin{array}{l}\text { Consultoria, cient., técn. } \\
\text { e similares }\end{array}$ & 53,5 & 51,4 & $-2,1$ & 60,8 & 56,5 & $-4,4$ & 37,9 & 40,6 & 2,7 \\
\hline $\begin{array}{l}\text { At. administ. e serv. de apoio } \\
\text { Adm. pública, defesa, }\end{array}$ & 52,3 & 49,2 & $-3,1$ & 53,8 & 50,4 & $-3,4$ & 38,2 & 35,2 & $-3,0$ \\
\hline seg. social & 35,4 & 41,2 & 5,8 & 35,3 & 41,1 & 5,8 & 55,6 & 53,8 & $-1,7$ \\
\hline Educação & 76,6 & 78,0 & 1,4 & 77,2 & 78,4 & 1,3 & 52,0 & 62,5 & 10,5 \\
\hline
\end{tabular}

As atividades de alojamento, restauração e similares também se destacam por pagarem o salário mínimo a mais de $20 \%$ do pessoal. 
Tabela 3 (continuação)

Mudanças nas taxas de feminização por setor e situação na profissão (2008-2014)

\begin{tabular}{|c|c|c|c|c|c|c|c|c|c|}
\hline \multirow{2}{*}{ Atividade principal } & \multicolumn{3}{|c|}{$\begin{array}{l}\text { Taxa de feminização - } \\
\text { Emprego Total }\end{array}$} & \multicolumn{3}{|c|}{$\begin{array}{c}\text { Taxa de feminização - } \\
\text { TPCO }\end{array}$} & \multicolumn{3}{|c|}{$\begin{array}{l}\text { Taxa de feminização - } \\
\text { Outras Situações }\end{array}$} \\
\hline & $\begin{array}{c}2008 \\
(\%)\end{array}$ & $\begin{array}{c}2014 \\
(\%)\end{array}$ & $\begin{array}{l}\text { Diferencial } \\
\text { (em p.p.) }\end{array}$ & $\begin{array}{c}2008 \\
(\%)\end{array}$ & $\begin{array}{c}2014 \\
(\%)\end{array}$ & $\begin{array}{l}\text { Diferencial } \\
\text { (em p.p.) }\end{array}$ & $\begin{array}{c}2008 \\
(\%)\end{array}$ & $\begin{array}{c}2014 \\
(\%)\end{array}$ & $\begin{array}{l}\text { Diferencial } \\
\text { (em p.p.) }\end{array}$ \\
\hline Saúde hum. e apoio social & 83,4 & 82,1 & $-1,3$ & 83,9 & 83,4 & $-0,5$ & 74,1 & 59,5 & $-14,6$ \\
\hline $\begin{array}{l}\text { At. artísticas, espetáculos, } \\
\text { desp. e recrea. }\end{array}$ & 40,9 & 42,6 & 1,7 & 43,2 & 45,8 & 2,6 & 31,5 & 26,3 & $-5,2$ \\
\hline Outros serviços & 71,9 & 72,6 & 0,7 & 70,4 & 69,1 & $-1,3$ & 74,3 & 77,6 & 3,3 \\
\hline Agregados domésticos & 98,9 & 97,9 & $-1,0$ & 98,6 & 98,1 & $-0,5$ & 99,7 & 89,2 & $-10,6$ \\
\hline
\end{tabular}

Fonte: Cálculos próprios. Com base nas Estatísticas do Emprego - 4.ํㅜ Trimestre de 2008 e 2014 (INE, 2009; 2015a).

As reduções no consumo, com impactos na restauração e hotelaria e no comércio por grosso e a retalho, causaram também perdas de emprego. No comércio, os homens foram os principais afetados, pois constituíam a maior parte da força de trabalho (55,6\%, em 2008). As suas perdas cifraram-se em $-18,3 \%$, mais do triplo dos $-5,4 \%$ de perdas das mulheres. Como na maior parte dos países do sul, e por contraste com os do norte, em Portugal quer a taxa de feminização quer a percentagem de trabalhadores/as jovens entre os 15 e os 24 anos está abaixo da média europeia neste setor. Este facto pode estar associado à maior incidência de emprego por conta própria, de trabalho a tempo inteiro e de contratos a termo nos países do sul (Eurofound, 2012). Prova de que o comércio atravessa um período de acelerada mudança é o aumento inusitado da taxa de feminização do trabalho por conta de outrem durante o período em análise (5,3 p.p.). Isto é tão ou mais importante na medida em que o setor representa cerca de $15 \%$ do emprego feminino e masculino.

Os setores onde ocorreu a maior feminização foram os das atividades imobiliárias (mais 5,7 p.p.), e o da administração pública (mais 5,8 p.p.). Há que ver, no entanto, que este setor tem uma composição enganadora, que nos induz em perceções erróneas quando o usamos como variável proxy para a administração pública. Os dados do emprego público mostram, no entanto, que o aumento da taxa de feminização foi apenas de 0,1 p.p., neste caso entre 2011 e 2014 (de 58,9\% para 59\%) (DGAEP, 2015).

Os ganhos líquidos de emprego em certos setores, particularmente educação e saúde, muito feminizados, num contexto de contração do emprego público ${ }^{7}$, são

Só no grupo do pessoal docente dos níveis de ensino não superior (infantil, básico e secundário), foram eliminados 23.089 postos de trabalho no setor público, entre 2011 e 2014. No setor da saúde, houve um aumento do pessoal médico ao serviço no setor público (mais 959) que, no entanto, não chegou a compensar as perdas verificadas no pessoal de enfermagem e outro pessoal técnico (2.569) (DGAEP, 2015). 
reveladores da crescente importância do investimento privado nestes setores (DGAEP, 2015) ${ }^{8}$. Entre os setores com mais peso no emprego (mais de $10 \%$ do emprego masculino ou do emprego feminino), o da saúde está entre aqueles em que se registou uma redução da taxa de feminização (-1,3 p.p.), conjuntamente com o alojamento, restauração e similares (-2,5 p.p.). Estas alterações contribuíram para atenuar a segregação sexual do emprego. Em sentido contrário, devemos assinalar a enorme redução das atividades agrícolas, que deixaram de ser um setor com participação equilibrada entre os dois sexos para passar a ser maioritariamente masculina, dado o recuo da taxa de feminização de $50,3 \%$ para $36,1 \%$.

Por fim, embora com pouco peso no total do emprego, vale a pena chamar a atenção para dois setores, pelas variações muito fortes das respetivas taxas de feminização, ainda que de sinal diferente. Trata-se do setor das atividades de informação e comunicação, com uma acentuada redução na taxa de feminização (-7.1 p.p. vs. $26,9 \%$ de emprego masculino), particularmente preocupante dada a predominância masculina neste setor de ponta (apenas 37,4\% de feminização em 2011), onde mais oportunidades de emprego têm surgido malgrado a recessão. No segundo setor em destaque, o imobiliário, passa-se precisamente o contrário os homens estão a deixar os seus empregos neste setor profundamente afetado pela crise (da construção), enquanto as mulheres estão a encontrar aí mais oportunidades, certamente menos atraentes que antes. $\mathrm{O}$ crescimento do emprego feminino a uma taxa de $23,2 \%$ está na base do aumento da feminização em 5,7 p.p. Embora com algum exagero, poderíamos dizer que estes dois setores são claros tradutores dos princípios da segregação sexual do emprego - melhores oportunidades para os homens em setores de ponta que oferecem melhores remunerações e carreiras e o inverso para as mulheres.

A tabela 4 mostra a taxa de mudança nos últimos anos, sublinhando os segmentos da força de trabalho que ganharam e os que perderam empregos. A tendência de aumento do trabalho a tempo parcial no caso dos homens, entre $2011 \mathrm{e}$ 2012 (Ferreira, 2014: 218), não se prolongou. Nesta tabela, o grande destaque vai para os ganhos das mulheres na obtenção de outros tipos de contrato (a partir de 2011, essencialmente contratos de prestação de serviços), especialmente os de carácter precário.

O modelo de especialização da economia portuguesa tem assentado nos setores de emprego pouco qualificado e mal pago, com particular ênfase nos setores do comércio e do turismo (incluindo alojamento e restauração). Isto explica os ganhos ao nível do emprego feminino (e de pessoas imigrantes) e os elevados níveis de trabalho a termo certo (apenas ultrapassado por Espanha). Em anos recentes, os contratos a termo certo correspondem a um em cada cinco

A divulgação em 2015 dos dados da administração pública por profissão e por sexo permitenos pensar que a hipótese mais provável é a da expansão do investimento privado na saúde e na educação e não, como defendido em Ferreira (2014), o facto de trabalhadores e trabalhadoras em situações contratuais precárias terem visto a sua situação legalizada. 
Tabela 4

Variação líquida de emprego (\%) por regime de trabalho, contrato e sexo (Portugal, 2011-2014)

\begin{tabular}{llr}
\hline \multicolumn{1}{c}{ População Empregada Total } & & $\mathbf{2 0 1 1 - 2 0 1 4}$ \\
\hline \multirow{2}{*}{ Tempo Inteiro } & Homens & $-10,7 \%$ \\
& Mulheres & $-1,9 \%$ \\
Tempo Parcial & Homens & $-3,1 \%$ \\
& Mulheres & $-12,5 \%$ \\
TRABALHADORES/AS POR CONTA DE OUTREM & & \\
Contrato Permanente & Homens & $-9 \%$ \\
Contrato Termo certo & Mulheres & $0,4 \%$ \\
& Homens & $-8,9$ \\
Outro tipo de contrato & Mulheres & $-8,8 \%$ \\
& Homens & $-17,7 \%$ \\
\hline
\end{tabular}

Fonte: Estatísticas nacionais. Inquérito ao Emprego 2011 e 2004. Cálculos próprios.

empregos. A distribuição por sexo das taxas de emprego a termo certo foi afetada pela crise, verificando-se que se, em finais de 2009 , a taxa era de $16,9 \%$ para os homens e 19,2\% para as mulheres, no final de 2014 a taxa era já 18,3\% e 17,5\%, respetivamente. Houve, portanto, uma redução do diferencial entre sexos deste tipo de contrato de trabalho, com um aumento muito mais acentuado nos homens e uma pequena redução da percentagem de mulheres.

Quanto ao desemprego, ele aumentou para todos os grupos etários ao longo da década, e níveis de qualificação, não obstante o melhor desempenho das pessoas diplomadas.

Em suma, podem destacar-se os seguintes grupos e setores económicos como os mais afetados pela crise:

- Trabalhadores e trabalhadoras mais jovens - o maior impacto - com uma taxa de desemprego que atingiu os 35\% no primeiro trimestre de 2012;

- Homens trabalhadores por conta de outrem;

- Mulheres trabalhadoras por conta própria, funcionárias públicas, empregadas domésticas e trabalhadoras familiares não remuneradas, trabalhadoras com contrato a termo certo;

- Setores da construção, indústria, agricultura, comércio e serviços domésticos.

Houve nos primeiros anos da crise uma tendência para a redução das horas trabalhadas, com a masculinização do trabalho a tempo parcial e o aumento da masculinização do subemprego visível. $\mathrm{O}$ contrato de trabalho a termo certo teve um papel de amortecedor da perda de emprego durante a crise, aumentando mais 
no caso dos homens e até diminuindo no caso das mulheres. Podemos, portanto, dizer que os homens se estão a tornar mais parecidos com as mulheres em termos de perfil de emprego, o que converge num fenómeno de «feminização da força de trabalho", que significa que o trabalho masculino se está a tornar tão flexível e precário, como o trabalho feminino tem sido. A estratégia é a de nivelar por baixo os padrões do emprego, feminizando o mercado de trabalho, não em termos numéricos, mas em termos substanciais e de regulação. Portugal suportou os custos do ajustamento onerando os segmentos mais precários do mercado de trabalho emprego a termo e trabalho por conta própria - usados como alavanca do ajustamento e restringindo a entrada de nova força de trabalho no mercado laboral.

\section{A crise e a resposta política}

Em termos de respostas governativas à situação podem distinguir-se duas fases. Na primeira metade de 2009, o governo português lançou medidas para ajudar empresas e indivíduos a lidar com os efeitos nefastos resultantes da redução de encomendas, das dificuldades de acesso ao crédito e da perda de rendimentos. A estratégia nacional de resposta à crise de emprego incluiu medidas dirigidas às empresas, para aumentar o emprego, e aos indivíduos, para lidarem com o desemprego. No geral, as medidas tomadas a nível nacional, e que a seguir se sistematizam, estavam em consonância com as orientações da União Europeia: manter as pessoas no emprego, aumentar as competências, aumentar o acesso ao emprego. Tratou-se de medidas com duas finalidades principais: de apoio aos rendimentos (aquisição de bens e serviços; redução dos impostos das empresas e dos impostos sobre os rendimentos pessoais; redução nos impostos indiretos e nas contribuições para a segurança social); de estímulo à economia (investimento em infraestruturas; aquisição pública de bens; transferências para os agregados familiares).

Estas medidas conduziram a um aumento enorme da despesa do Estado, o que elevou o deficit público em 10,1\% do PIB e acelerou a crise da dívida pública. Quando Portugal pediu assistência financeira internacional, as negociações foram concluídas com um memorando de entendimento para uma estratégia de consolidação fiscal, profundas reformas do mercado de trabalho, do sistema judicial, das redes de serviços básicos e aos setores da habitação e outros serviços, e de salvaguarda do setor financeiro (Comissão Europeia, 2011).

De 2010 em frente, as principais medidas de combate ao défice público foram as seguintes:

1. Reduções no que passou a ser designado como «privilégios dos/as trabalhadores/as da função pública» (segurança de emprego, salários, pensões) - cortes salariais, congelamento de carreiras, alterações nas políticas de aposentação; 
2. Reestruturação da administração pública, fundindo ou eliminando postos de trabalho em comissões/agências, postos de gestão intermédia e outras funções;

3. Aumento de impostos diretos e indiretos e do preço dos transportes, gás e eletricidade;

4. Privatização total ou parcial de empresas públicas - eletricidade e águas, televisão, transportes aéreos e outras;

5. Desregulação das relações laborais facilitando os despedimentos e flexibilizando os horários de trabalho e a mobilidade laboral.

A estratégia do governo liderado pelo PSD em coligação com o CDS para lidar com a crise passou, a partir de meados de 2011, pelo aumento das exportações de bens transacionáveis reforçando a competitividade através da redução salarial. O modelo de especialização subjacente a esta estratégia intensificou o modelo tradicionalmente dominante da economia portuguesa - baixos salários para produção de bens para consumo final com pouco valor acrescentado. A mão-de-obra feminina é particularmente desejável nestes setores exportadores, que, no entanto, não oferecem qualidade de emprego. Ao invés, a queda sistemática da feminização das ciências, tecnologias e das engenharias afastará ainda mais as mulheres dos sectores das indústrias e serviços com perfil tecnológico mais avançado. É particularmente preocupante a fuga de mulheres das engenharias, que representou uma queda de mais de 9 pontos percentuais nas taxas de feminização dos respetivos cursos superiores. Também ilustrativa é a queda de 7,1 pontos percentuais na feminização do setor da informação e comunicação (tabela 3).

A perda de emprego tem influenciado particularmente o altamente feminizado setor da administração pública, tradicionalmente na vanguarda das políticas de conciliação trabalho-família. Entre dezembro de 2011 e dezembro de 2014, 30.551 homens e 40.814 mulheres perderam os seus empregos na função pública. Quem ficou viu as suas carreiras congeladas, os horários e cargas de trabalho intensificados e o seu poder de compra diminuído, devido aos cortes dos seus salários e ao aumento dos impostos. Segundo os cálculos de Eugénio Rosa, a variação (2010-2014) do poder de compra da remuneração base média mensal da Função Pública foi negativa $(-24,4 \%)$, contados o valor nominal das remunerações, o aumento dos impostos (diretos e indiretos) e a perda de poder de compra por via da inflação (Rosa, 2014) ${ }^{9}$.

Diferentes análises demonstraram o efeito positivo do setor público no emprego feminino (Estévez-Abe e Hethey, 2010), e não é por acaso que, em países

O valor a que Rosa chegou é apenas uma média. Se fizermos incidir os cálculos sobre postos de trabalho com salários mais altos, chegaremos a um montante bastante superior. A título ilustrativo, se compararmos a remuneração líquida mensal de um/a docente universitário/a, com a categoria de professor/a auxiliar, em dezembro de 2008 e de 2014, mostra uma quebra de $24,5 \%$, não contabilizando perdas decorrentes da inflação e do congelamento da carreira. 
com mais elevados níveis de vida e maior igualdade entre mulheres e homens, o emprego no setor público representa um quarto a um terço do emprego total. A redução do emprego público pode significar uma descida no índice de «igualdade de género» e nos rendimentos familiares e na autonomia das mulheres. Em 2000, as mulheres empregadas no setor privado contribuíam com $33 \%$ para o rendimento do agregado, e as que trabalhavam no setor público com $43 \%$ (Coelho, 2010). Além disso, as mudanças no emprego público também têm impactos nas perspetivas das mulheres mais desfavorecidas, especialmente aquelas que eram contratadas para o trabalho doméstico por parte de mulheres dos quadros da função pública. Os cortes nos salários na função pública reduzem a procura de trabalho doméstico e as oportunidades de trabalho das mulheres menos qualificadas (Coelho, 2010). Em 2008, 7,2\% de todo o emprego feminino recaía na categoria «agregados privados com pessoas empregadas», tendo sido eliminados 59.000 postos de trabalho, até 2014, e representando agora uns meros 5,2\%.

A redução da procura de emprego doméstico significa, também, que as mulheres de classe média estão a fazer mais trabalho doméstico e familiar, agravando a sua sobrecarga de trabalho e responsabilidades. A maior consagração das mulheres ao trabalho doméstico, sem uma reconfiguração dos padrões de divisão sexual de trabalho que implique maior partilha com outros elementos da família, pode vir a significar um relativo desinvestimento nas carreiras profissionais, ameaçando o seu estatuto social.

\section{Para onde caminhamos?}

Estamos, portanto, a viver em Portugal tempos de aumento do desemprego e da precarização, de aumento dos tempos de trabalho e de deterioração das condições de trabalho, em geral; de forte redução do rendimento disponível das famílias, por via da degradação dos salários e de outros rendimentos (como sejam as transferências da segurança social), do aumento das contribuições e impostos e dos preços de bens essenciais, como os combustíveis e a eletricidade. Tais alterações configuram a reestruturação do mercado de trabalho e do regime de bem-estar social, com forte impacto na divisão sexual de trabalho, nomeadamente entre trabalho pago e não-pago.

Onde é que as mudanças identificadas nos levarão, ou quem está a pagar a crise, são questões pertinentes. Os segmentos mais frágeis e vulneráveis da população enfrentam dificuldades agravadas. A população jovem não consegue entrar no mercado de trabalho, a não ser em condições altamente instáveis e precárias, por isso, parte emigra. A posse de diplomas de ensino superior já não é uma salvaguarda, nem assegura mobilidade social, defraudando expectativas colocadas no sistema de ensino. O desemprego de longa duração aumenta, bem como a desproteção das pessoas nessa condição que viram suprimidos os direitos a subsídios e proteção social. Reduziram-se também os números do emprego por 
conta própria, devido à crise e porque as novas obrigações fiscais tornaram os «falsos recibos verdes» menos atrativos para entidades empregadoras. A perda de oportunidades de emprego no setor público, em declínio desde 2005, reflete-se também negativamente na posição das mulheres no mercado laboral.

Voltando à hipótese formulada no início deste texto, percebe-se que, em Portugal, devido à «crise», se vive um retrocesso nas tentativas de abandonar o tradicional regime de bem-estar social do sul da Europa iniciadas por medidas governativas das últimas décadas. As evidências empíricas deste retrocesso são múltiplas. Medidas desenhadas para combater a crise tiveram fortes impactos no sistema de bem-estar ${ }^{10}$. Entre elas contam-se os cortes nos subsídios às famílias e outros apoios sociais; os cortes nas transferências, mudanças na filosofia de proteção social reduzindo as taxas de cobertura e de reposição do rendimento, restrições nos critérios de elegibilidade para acesso a subsídios e reforço do critério de condição de recursos. Ao nível das pensões, as medidas também foram altamente penalizantes, designadamente, o aumento da idade da reforma, os cortes nas taxas de reposição do rendimento, a imposição de novas contribuições para pensionistas do setor público, e reduções nos benefícios fiscais.

Contrastando com as políticas de cortes, em 2014, o governo lançou, como medida de apoio à natalidade, a «benesse» para o funcionalismo público da possibilidade de se poder trabalhar em meio-tempo, sem perda de tempo de serviço efetivo, por $60 \%$ do salário ${ }^{11}$. Dirigindo-se sobretudo «às mães, que gostam de ter mais tempo com os seus filhos»

A seletividade passou a ser o princípio da distribuição da proteção social, em vez do universalismo. A intensificação da prova de recursos para a proteção social reforça a subsidiariedade familiar e reduz a autonomia das mulheres a nível individual, social e político. A sua cidadania vê-se reduzida por uma reprivatização da proteção social que reenvia as mulheres para o isolamento da família, dependência económica e estatutária e para o desempenho de papéis sexuais convencionais. Paradoxalmente, tendo em conta os investimentos públicos das últimas décadas em equipamentos sociais de apoio aos cuidados de pessoas idosas, crianças e outras dependentes, com o recuo brusco do bem-estar formal, reforça-se a sociedade providencial informal, a solidariedade informal provida

10 As análises de González e Figueiredo (2014) e de Zartaloudis (2014) chamam a atenção para os elevados custos sociais que cortes na proteção social acarretam num contexto de sistemas de proteção social ainda incipientes, que procuram a convergência com os vigentes nos países de maior desenvolvimento.

11 Mota Soares, então Ministro da Ministro da Solidariedade, Emprego e Segurança Social, justificou a medida deste modo: "Hoje uma mulher que pretenda ser mãe, mais do que a disponibilidade financeira, reclama por disponibilidade para uma maior dedicação. Se tempo tivesse para os acompanhar teria mais filhos», declaração produzida em 13 de abril de 2013, altura em que deu início à preparação da medida que viria a ser lançada em 2015 (cf. http://www.noticiasaominuto.com/economia/59556/governo-quer-criar-part-times-para-que-haja-tempo-defazer-filhos). 
pela família, pelas redes informais que, como se sabe, são tecidas pelo trabalho não remunerado das mulheres (Portugal, 2008; Frade e Coelho, 2015). Como defendem Margarita León e Mauro Migliavacca (2013), para os casos de Espanha e Itália, também em Portugal podemos ver o reforço do familismo nestas tendências, sobretudo por via do aumento da prestação de cuidados a cargo das mulheres, especialmente à população idosa (tarefa menos partilhada do que os cuidados às crianças) e à população mais jovem que não consegue dar corpo aos seus projetos de autonomia pessoal, em face da falta de emprego ou da grande precariedade de emprego com que se vê confrontada. Segundo aquelas autoras, «a co-residência [entre gerações] na Europa do Sul é uma maneira de transferir recursos de pais para filhos e vice-versa» (León e Migliavacca, 2013: 37), e tem como resultado a diminuição da necessidade de intervenção do Estado.

A desproteção social no desemprego agravou-se, sendo que, em 2014, 68,6\% das pessoas inscritas não tinha subsídio de desemprego, para além da redução nos montantes do subsídio pago. São as famílias quem tem suportado e compensado esta desproteção, especialmente no caso das pessoas jovens que enfrentam barreiras no acesso ao mercado de trabalho e situações laborais altamente precárias e inseguras. Prolongar a dependência da família a nível habitacional e financeiro tem sido a única solução para a população jovem, especialmente aquela que não saiu do país à procura de oportunidades, não contando, portanto, para o quase meio milhão de pessoas que emigrou entre 2011 e 2014. Como concluíram Catarina Frade e Lina Coelho (2015), a solidariedade intergeracional na família foi uma estratégia fundamental para a manutenção da estabilidade social em contexto de crise. Foram as famílias quem suportou os custos do desemprego, da precariedade, dos cortes bruscos da proteção formal, amortecendo os impactos mais severos da crise e das medidas de austeridade impostas. E são ainda elas, o mesmo seja dizer as mulheres, que cuidam das crianças e pessoas idosas retiradas das respetivas instituições de acolhimento por dificuldades de pagamento das mensalidades. Se quisermos qualificar este acentuar do familismo, diríamos, com Mary Daly (2011), que se regista uma refamilização de responsabilidades que haviam sido externalizadas para o mercado, com o apoio do Estado, no caso vertente.

Numa sociedade de consumidores/as, o Estado Providência é menos útil do que em uma sociedade de produtores/as (Bauman, 2010). Naquele tipo de sociedade não há necessidade de apoiar a reprodução da força de trabalho, além do que não existem empregos disponíveis para a ocupar. Por isso o investimento social deixa de ser visto como necessário elemento impulsionador do sucesso e desenvolvimento sustentado das sociedades. As pessoas pobres são assim colocadas sob vigilância e é criada uma narrativa de «merecimento» de apoio e de benefícios sociais. Trabalhadores/as e direitos transformam-se apenas em mais uma variável nos ajustamentos a fazer no mercado, desnacionalizando-se (Ferreira, 2012). Os cortes nas despesas sociais encaixam nesta ideologia. O XIX Governo Constitucional (2011-2015) afirmou perentoriamente a ideia de que o 
investimento social apenas deve ser aceite num quadro de empobrecimento e de baixíssimos níveis de vida.

Relativamente às desigualdades entre mulheres e homens, durante a crise, $\mathrm{e}$ fruto dos impactos das medidas de austeridade, assistiu-se a um atenuar do diferencial ao nível do desemprego, que não atingiu as mulheres tão fortemente durante os dois primeiros anos da crise. Verificou-se mesmo uma «feminização» das condições laborais dos homens, numa espécie de nivelação por baixo das mesmas, que os aproximou da situação tradicionalmente mais precária e insegura do emprego feminino. Não obstante estes dois aspetos, a discriminação laboral persiste como marca de um mercado de trabalho especialmente desvantajoso e adverso para as mulheres. Os ganhos de emprego feminino acontecem em setores e categorias de baixas remunerações, tendo mesmo inicialmente aumentado os diferenciais salariais.

No contexto dos novos arranjos de welfare mix que estão a emergir destas políticas, importa perceber quais serão os seus impactos sobre os padrões de comparticipação dos seus três pilares fundamentais - o Estado, o mercado e a família - e que lugar neles ocuparão mulheres e homens. O desafio deverá passar por determinar em que medida podemos influenciar a criação de cidadania e de bem-estar que não representem uma perda de autonomia para as mulheres em termos individuais, sociais e políticos. Confiar, mais uma vez, nas mulheres para garantirem a proteção social e os cuidados é fazer renascer o velho modelo do sul da Europa que tinha começado a desaparecer em Portugal, acentuando um retorno a um passado desigualitário e assimétrico.

\section{Referências bibliográficas}

ACT - Autoridade para as Condições de Trabalho (2015), Atividade de Inspeção do Trabalho - Relatório 2014, [em linha] Disponível em: http://www.act.gov.pt/(pt-PT)/crc/PublicacoesElectronicas/InspeccaodoTrabalho/Documents/RelatorioAI2014.pdf [consultado em 15 de outubro de 2015].

Bauman, Zygmunt (2010), Living on Borrowed Time - Conversation with Citlali Rovirosa-Madrazo, Cambridge, Polity Press.

Campos, Maria Manuel; Pereira, Manuel C. (2009), «Salários e Incentivos na Administração Pública em Portugal», Boletim Económico do Banco de Portugal, Verão, 61-83.

Coelho, Lina (2010), «Mulheres, Família e Desigualdade», Dissertação de Doutoramento, Universidade de Coimbra (FEUC).

Daly, Mary (2011), «What Adult Worker Model? A Critical Look at Recent Social Policy Reform in Europe from a Gender and Family Perspective», Social Politics 18(1), 1-23.

DGAEP - Direção-Geral da Administração e do Emprego Público (2.ำ Trim. 2015), Síntese Estatística do Emprego Público, Lisboa, Ministério das Finanças [em linha] disponível em: http://www.dgaep.gov.pt/index.cfm?\&OBJID=da5b5dbb-6ace-4d45-9a10315cedc919b8 [consultado em 1 de novembro de 2015].

DGAEP - Direção-Geral da Administração e do Emprego Público (outubro 2012), Boletim Estatístico do Emprego Público n. ํ 07, [em linha] disponível em: http://www.dgaep. 
gov.pt/upload//DEEP/BOEP07/DGAEP-DEEP BOEP 07.pdf [consultado em 2 de agosto de 2015].

Estévez-Abe, Margarita; Hethey, Tanja (2010), «Women's Work, Family Income and Public Policy». Paper presented to the conference on «Inequality and the Status of the Middle Class: Lessons from the Luxembourg Income Study», University of Luxembourg, June 28-30.

Eurofound (European Foundation for the Improvement of Living and Working Conditions) (2012), Working conditions in the retail sector, [em linha] Disponível em: http://www.eurofound.europa.eu/ewco/studies/tn1109058s/tn1109058s_1.htm [consultado em 18 de agosto de 2012].

Ferreira, António Casimiro (2012), Sociedade de Austeridade e Direito do Trabalho de Exceção, Porto, Vida Económica.

Ferreira, Virgínia (1994), «Women's employment in the European semi-peripheral countries: analysis of the Portuguese case,» Women's Studies International Forum 17(2/3), 141-55.

Ferreira, Virgínia (2011), Engendering Portugal: social change, state politics and women's social mobilization, in António Pinto (ed.), Contemporary Portugal, Boulder, Columbia University Press, 153-192.

Ferreira, Virgínia (2014), «Employment and austerity: Changing welfare and gender regimes in Portugal», in Maria Karamessini and Jill Rubery (Eds.), Women and Austerity The Economic Criis and the Future for Gender Equality, Londres e Nova Iorque, Routledge, 207-227.

Frade, Catarina; Coelho, Lina (2015), «Surviving the Crisis and Austerity: The Coping Strategies of Portuguese Households», Indiana Journal of Global Legal Studies 22(2), 631-664.

GEE - Gabinete de Estratégia e Estudos (2015), Boletim Estatístico - Agosto de 2015, Lisboa, Ministério da Economia [em linha] disponível em http://www.gee.min-economia.pt/ [consultado em 11 de setembro de 2015].

González, Pilar; Figueiredo, António (2014), «The European Social Model in a Context of Crisis and Austerity in Portugal», in Daniel Vaughan-Whitehead (ed.), The European Social Model in Times of Economic Crisis and Austerity Policies, Geneva, International Labour Organization, 291-340.

GPEARI (2011), «Diplomados do Ensino Superior [2000-2001 a 2009-2010]», [em linha] Disponível em: http://www.gpeari.mctes.pt/es> [consultado em 5 de março de 2012].

INE - Instituto Nacional de Estatística (2009; 2012), Estatísticas do Emprego - 4º trimestre, [em linha] disponível em: http://www.ine.pt/xportal/xmain?xpid=INE\&xpgid= ine publicacoes [consultado em 17 de julho de 2012].

INE - Instituto Nacional de Estatística (2015a), Estatísticas do Emprego - 4⿳o - trimestre de 2014, [em linha] disponível em: http://www.ine.pt/ [consultado em 23 de junho de 2015].

INE - Instituto Nacional de Estatística (2015b), Destaques - Saldos natural e migratório negativos atenuam-se face ao ano anterior [em linha] disponível em: http://www.ine.pt/ [consultado em 1 de novembro de 2015].

León, Margarita; Migliavacca, Mauro (2013), «Italy and Spain: Still the Case of Familistic Welfare Models?», Population Review 52(1), 25-42.

OCDE (2011) Education at a Glance, [em linha] disponível em: http://www.oecd.org/ dataoecd/61/61/48630790.pdf [consultado em 5 de maio de 2012].

Portugal, Sílvia (2008), «As mulheres e a produção de bem-estar em Portugal», Oficina do CES, n. ${ }^{\circ} 319$. 
Rosa, Eugénio (2014), «A Remuneração Media Liquida Total dos Trabalhadores da Função Pública é Apenas de 976? em 2014, o Suplemento Medio é Inferior a 94?/Mês, e o Poder de Compra na Administração Pública já Diminuiu 24\% desde 2010» [em linha] disponível em: https://www.eugeniorosa.com/Sites/eugeniorosa.com/ Documentos/2014/36-2014-remuneracaofp.pdf [consultado em 15 de agosto de 2015].

Rubery, Jill (2013), «Public sector adjustment and the threat to gender equality», in Daniel Vaughan-Whitehead (ed.), Public Sector Shock, ILO /Edward Elgar, 43-83.

Santos, Boaventura de Sousa (2011), Portugal: Ensaio contra a autoflagelação, Coimbra, Almedina.

Zartaloudis, Sortirios (2014), «The Impact of the Fiscal Crisis on Greek and Portuguese Welfare States: Retrenchment before the Catch-up?», Social Policy $\mathcal{E}$ Administration $48(4), 430-449$.

Virgínia Ferreira. Doutorada em Sociologia; Docente na Faculdade de Economia e investigadora do CES-UC. Membro fundador da APEM, e membro do Expert Group on Gender and Employment da Comissão Europeia. Publicou recentemente com Rosa Monteiro (2013), Trabalho, igualdade e diálogo social: Estratégias e desafios de um percurso (Lisboa, CITE).

URL: http://www.ces.uc.pt/investigadores/cv/virginia ferreira.php; virginia@fe.uc.pt

Rosa Monteiro. Doutorada em Sociologia. Docente no Instituto Superior Miguel Torga e investigadora do CES-UC. A sua tese incidiu sobre «Feminismo de Estado em Portugal». Publicou recentemente (com Luísa Agostinho e Fernanda Daniela, 2015), «Um diagnóstico da desigualdade de gênero num município em Portugal: estruturas e representações», Revista de Administração Pública 49(2), 423-446.

URL: http://www.ces.uc.pt/investigadores/cv/rosa_monteiro.php; monteiro.rosa14@gmail.com

Centro de Estudos Sociais, Colégio de S. Jerónimo, Largo D. Dinis Apartado 3087 3000-995 Coimbra, Portugal

Artigo recebido em 23 de julho de 2015 e aceite para publicação em 19 de outubro de 2015. 